\title{
Comments on "Anesthesia for interventional pulmonology procedures: a review of advanced diagnostic and therapeutic bronchoscopy"
}

\author{
Peter Biro, MD, DESA
}

Received: 12 April 2018/Revised: 16 April 2018/Accepted: 16 April 2018/Published online: 6 June 2018

(C) Canadian Anesthesiologists' Society 2018

\section{To the Editor,}

The recent review article by de Lima et al. ${ }^{1}$ delivers a well-written overview of the anesthesia-related aspects of interventional pulmonology. This includes a detailed section about access to the airway and ventilation. As jet ventilation is a widely used technique in this context, the authors dedicated a detailed portion of their review to this method. While much of what the authors state is factual and clear about many aspects of anesthesia for bronchologic interventions, the section about jet ventilation seems to be based more on information extracted from outdated literature and less from personal experience. As a result, some statements appear incorrect and/or are in opposition to actual practice-e.g., they state that "Based on the Venturi principle and other physical properties, the system achieves a high fraction of inspired oxygen $\left(\mathrm{F}_{\mathrm{I}} \mathrm{O}_{2}\right.$ by administering high-pressure gas through an open system". Their statement that jet ventilation depends on the Venturi principle, which would in turn enable a high $\mathrm{F}_{\mathrm{I}} \mathrm{O}_{2}$, is a fundamental misconception and seems to reflect an uncritical repetition of phrases from inaccurate sources. In reality, the Venturi principle has no relevance for jet ventilation, and the closest effect that it resembles is "entrainment". ${ }^{2}$ This mechanism has a strong impact on jet ventilation, but instead of increasing $\mathrm{F}_{\mathrm{I}} \mathrm{O}_{2}$ it decreases it by diluting the jet gas (which usually contains a high oxygen concentration) with ambient air.

This letter is accompanied by a reply. Please see Can J Anesth 2018; 65: this issue.

P. Biro, MD, DESA $(\bowtie)$

Institute of Anesthesiology, University Hospital Zurich, Zurich, Switzerland

e-mail: peter.biro@usz.ch
Nevertheless, there is also a benefit of entrainment. By increasing the injected gas volume into the airway and consequently enlarging tidal volumes, entrainment facilitates $\mathrm{CO}_{2}$ exhalation.

The statement "technical settings (e.g., driving pressure and duration) of the jet ventilator can be adjusted according to intraoperative blood-gas analysis or based on the quantity of conventional ventilation periods required to achieve adequate $\mathrm{SaO}_{2}$ " could also be modified to improve accuracy. The settings are not "driving pressure and duration", but rather "driving pressure and inspiratory duration" (or perhaps even better, the "I/E-ratio"). While blood-gas analysis results as well as pulse oximetry are correctly stated, ${ }^{3}$ the notion that ventilation might be adjusted according to "the quantity of conventional ventilation periods required to achieve adequate $\mathrm{SaO}_{2}$ " is at best vague and does not contain any applicable specific guiding information.

The statement "recommendations to prevent barotrauma include maintaining a driving pressure around 1.5 bar (approximately $20 \mathrm{PSI}$ ) and limiting inspiration duration to $30-40 \%$ of the respiratory cycle" is arguably of little help either. For example, any level of driving pressure can cause barotrauma if the outflow of gas is hindered. Accordingly, it does not make any difference if the driving pressure was set at 2,1 , or even as low as 0.5 bar only. ${ }^{4}$ The real protection against barotrauma is continuous measurement of the airway pressure using a separate lumen and/or intermittently in the jet line. When using rigid bronchoscopy equipment, usually the pressure measurement can be done in the jet line alone. The essential safety feature in this context is an automatic shutdown of the ventilator if a user-set airway pressure limit has been surpassed. Furthermore, limiting the driving pressure to 1.5 bar would exclude a very large proportion 
of patients from being treated this way (e.g., those with obstructive lung diseases, obesity, or both). These patients still can be sufficiently ventilated, but often need driving pressures far above 2 (or even $>3$ ) bar. ${ }^{4}$ The best approach to individualizing driving pressure is via a stepwise increase of the pressure level to the value that prevents a raise of the partial pressure of carbon dioxide above baseline. The additional assumption that a high autopositive end-expiratory pressure (PEEP) might cause barotrauma is unsubstantiated as long as there is no relevant hindrance for the gas outflow. While auto-PEEP increases with ventilation frequency and usually remains at tolerable levels below $10 \mathrm{mmHg}$, a sudden raise in airway pressure caused by outflow obstruction is something very different and certainly dangerous-i.e., this is true "gas trapping". 5

Finally, there is no evidence for the statement that an "extremely high respiratory frequency" might cause damage to the mucocilliary epithelium. This is more a typical complication of jet ventilation that uses unhumidified, cold, and dry gas. ${ }^{6}$ This can be prevented by using a jet ventilator that automatically adapts air humidification and warming to the delivered jet gas such as the Acutronic Monsoon (Acutronic Medical Systems, Hirzel, Switzerland). The other modern jet ventilator mentioned in the article, the TwinStream Respirator ${ }^{\mathrm{TM}}$ (Carl Reiner, Vienna, Austria), needs to be connected to an external humidification system to protect the respiratory mucosa from damage.

Conflicts of interest None declared.

Editorial responsibility This submission was handled by Dr. Hilary P. Grocott, Editor-in-Chief, Canadian Journal of Anesthesia.

\section{References}

1. de Lima A, Kheir F, Majid A, Pawlowski J. Anesthesia for interventional pulmonology procedures: a review of advanced diagnostic and therapeutic bronchoscopy. Can J Anesth 2018. DOI: https://doi.org/10.1007/s12630-018-1121-3.

2. Buczkowski PW, Fombon FN, Lin ES, Russell WC, Thompson JP. Air entrainment during high-frequency jet ventilation in a model of upper tracheal stenosis. Br J Anaesth 2007; 99: 891-7.

3. Baer GA, Paloheimo M, Rahnasto J, Pukander J. End-tidal oxygen concentration and pulse oximetry for monitoring oxygenation during intratracheal jet ventilation. J Clin Monit 1995; 11: 373-80.

4. Biro $P$. Jet Ventilation for surgical interventions in the upper airway. Anesthesiology Clin 2010; 28: 397-409.

5. Desruennes E, Bourgain JL, Mamelle G, Luboinski B. Airway obstruction and high-frequency jet ventilation during laryngoscopy. Ann Otol Rhinol Laryngol 199; 100: 922-7.

6. Dias NH, Martins RH, Braz JR, Carvalho LR. Larynx and cervical trachea in humidification and heating of inhaled gases. Ann Otol Rhinol Laryngol 2005; 114: 411-5. 